\title{
BMJ A nationally representative survey of Open healthcare provider counselling and provision of the female condom in South Africa and Zimbabwe
}

\author{
Kelsey Holt, ${ }^{1}$ Kelly Blanchard, ${ }^{2,3}$ Tsungai Chipato, ${ }^{4}$ Taazadza Nhemachena, ${ }^{4}$ \\ Maya Blum, ${ }^{5}$ Laura Stratton, ${ }^{5}$ Neetha Morar, ${ }^{6}$ Gita Ramjee, ${ }^{6}$ Cynthia C Harper ${ }^{5}$
}

To cite: Holt K, Blanchard K, Chipato $\mathrm{T}$, et al. A nationally representative survey of healthcare provider counselling and provision of the female condom in South Africa and Zimbabwe. BMJ Open 2013;3:e002208. doi:10.1136/bmjopen-2012002208

- Prepublication history for this paper are available online. To view these files please visit the journal online (http://dx.doi.org/10.1136/ bmjopen-2012-002208).

Received 11 October 2012 Revised 30 January 2013 Accepted 31 January 2013

This final article is available for use under the terms of the Creative Commons Attribution Non-Commercial 2.0 Licence; see http://bmjopen.bmj.com

For numbered affiliations see end of article.

Correspondence to

Kelsey Holt;

keh125@mail.harvard.edu

\section{ABSTRACT}

Objectives: Female condoms are the only femaleinitiated HIV and pregnancy prevention technology currently available. We examined female condom counselling and provision among providers in South Africa and Zimbabwe, high HIV-prevalence countries.

Design: A cross-sectional study using a nationally representative survey.

Setting: All facilities that provide family planning or HIV/sexually transmitted infection (STI) services.

Participants: National probability sample of 1444 nurses and physicians who provide family planning or HIV/STI services.

\section{Primary and secondary outcome measures:}

Female condom practices with different female patients, including adolescents, married women, women using hormonal contraception and by HIV status. Using multivariable logistic analysis, we measured variations in condom counselling by provider characteristics.

Results: Most providers reported offering female condoms (88\%; 1239/1415), but perceived a need for novel female barrier methods for HIV/STI prevention (85\%; 1191/1396). By patient type, providers reported less frequent female condom counselling of adolescents $(55 \% ; 775 / 1411)$, women using hormonal contraception (65\%; 909/1409) and married women (66\%; 931/1416), compared to unmarried (74\%; $1043 / 1414)$ or HIV-positive women (82\%; 1161/1415). Multivariable results showed providers in South Africa were less likely to counsel women on female condoms than in Zimbabwe $(0 \mathrm{R}=0.48,95 \% \mathrm{Cl} 0.35$ to 0.68 , $\mathrm{p} \leq 0.001)$. However, South African providers were more likely to counsel women on male condoms $(\mathrm{OR}=2.39,95 \% \mathrm{Cl} 1.57$ to $3.65, \mathrm{p} \leq 0.001)$. Nurses counselled patients on female condoms more frequently than physicians $(0 \mathrm{R}=5.41,95 \% \mathrm{Cl} 3.26$ to $8.98, p \leq 0.001)$. HIV training, family planning training, location (urban vs rural) and facility type (hospital vs clinic) were not associated with greater condom counselling.

Conclusions: Female condoms were integrated into provider counselling and care, although providers reported a need for new female-initiated multipurpose prevention technologies, suggesting female condoms

\section{ARTICLE SUMMARY}

\section{Article focus}

- A cross-sectional study examining current female condom (FC) counselling and provision practices among a nationally representative sample of healthcare providers in South Africa and Zimbabwe.

- Assessment of whether providers view FCs as more appropriate for certain types of patients, and how their FC practices varied compared with those for male condoms.

Key messages

- Most providers reported offering FCs (more so in Zimbabwe than in South Africa) but perceived a need for novel female barrier methods for HIV/ sexually transmitted infection prevention, suggesting FCs do not meet all patient/provider needs or are not adequately well known or accessible.

- Providers reported less-frequent FC counselling of adolescents, women using hormonal contraception and married women, compared with unmarried or HIV-positive women, suggesting the need for training, emphasising the importance of FC counselling with all women.

- Providers should be included in HIV training efforts to raise awareness of new and existing products.

Strengths and limitations of this study

- This is the first nationally representative survey in South Africa or Zimbabwe examining FC counselling and provision and we obtained high response rates; thus, we are able to generalise to the entire provider populations of these two high HIV prevalence countries.

- Potential social desirability bias may have influenced responses towards more comprehensive levels of prevention counselling.

do not meet all patient/provider needs or are not adequately well known or accessible. Providers should be included in HIV training efforts to raise awareness of new and existing products, and encouraged to educate all women. 


\section{INTRODUCTION}

There is growing recognition that no single intervention will be sufficient to halt the HIV epidemic and that combination prevention strategies tailored to the needs of specific populations have the most potential for decreasing HIV infection rates. ${ }^{1}$ The female condom (FC) is the only available alternative to the male condom that provides protection from both HIV/sexually transmitted infection (STI) infection and pregnancy, and it is a method that women can initiate. A review of research on the FC concluded that increased access to the method leads to an increase in protected sex in a population, and decreased STI incidence. ${ }^{2}$ There have been promising results from recent clinical trials testing the effectiveness of novel woman-initiated methods of HIV prevention, including microbicides ${ }^{3}$ and pre-exposure prophylaxis, which were recently endorsed by the Centers for Disease Control and Prevention (CDC) in the USA for use by heterosexual women at very high risk for HIV infection (eg, women with HIV-positive sex partners). ${ }^{4}$ However, conclusive proof of effectiveness and registration of a new woman-initiated HIV-prevention product recommended for widespread use is unlikely for a number of years, and the FC will remain an important option for women who desire pregnancy prevention and STI protection from a single product.

In sub-Saharan Africa, women are at increased risk of $\mathrm{HIV} / \mathrm{AIDS}$ and heterosexual sex is the predominant mode of transmission. ${ }^{5}$ HIV prevalence among women was estimated at $33 \%$ in the peak ages (25-29 years) in South Africa in 2008 and $29 \%$ in Zimbabwe (30-39 years) in 2010-2011. ${ }^{6}$ Among young people aged 15-24, HIV prevalence was $8.6 \%$ in South Africa in 2008 and $5.5 \%$ in Zimbabwe in 2010-2011. ${ }^{6} 7$ Additionally, 24\% of married women and $9 \%$ of never-married women in sub-Saharan Africa have an unmet need for contraception-rates higher than elsewhere in the developing world. ${ }^{8}$ In South Africa and Zimbabwe, reported use of the FC is less than $1 \%$ compared with 4-6\% use of male condoms among married women in peak ages of HIV prevalence (25-29 years in South Africa and 30-39 years in Zimbabwe). ${ }^{79}$

Since the US Food and Drug Administration (USFDA) approved the first available product - the FC1 - in 1993, there has been a lack of commitment and resources to expand access to the FC among the international policy community. ${ }^{10}$ In 2009, the USFDA approved a secondgeneration FC called FC2 made of synthetic latex rather than polyurethane. The FC2 is less expensive and makes less noise when used; ${ }^{10}$ other new FC technologies are in development and could reduce costs further. In addition, the 2010 and 2011 US President's Emergency Plan for AIDS Relief (PEPFAR) Fiscal Year Country Operational Plan Guidance specifically mentioned the importance of FCs in country programme plans and the Caucus on New and Underused Reproductive Health Technologies recently named the FC as one of several 'underused' reproductive health technologies. ${ }^{11}{ }^{12}$ These new products and policy developments are positive signs of increased support for the FC.
Healthcare provider participation, however, is essential to the success of FG programmes. Even if countries procure significant supplies, women and men may have limited knowledge and access if providers do not discuss and provide FCs. Unlike the male condom, the FC is typically obtained through provider contact (not dispensers) in the public sector with no cost to the user, although in some settings there is also a strong presence of social marketing campaigns. Training and accurate information from providers could increase acceptability and sustained use of the FC. ${ }^{10}$

Few studies have examined counselling and provision practices for FCs in sub-Saharan Africa. Three early case studies exploring family planning providers' attitudes about the FC in South Africa and Nigeria (where the FC was not yet introduced in the public sector), and the USA found that US providers lacked knowledge on the FC despite product availability and saw the method as appropriate only for certain women, such as sex workers or HIV-positive women. ${ }^{13}$ In the USA and South Africa, providers reported negative attitudes about the aesthetics and use of the FC, although providers in South Africa were more enthusiastic after receiving training. In a study of voluntary counselling and testing counsellors in Kenya, many counsellors recognised the need for a female-initiated prevention method but felt uncomfortable with FCs or expressed concern about counselling when FCs were not widely available. ${ }^{14}$ In another small qualitative study of provider FC opinions in Kenya, several healthcare providers reported support for FCs owing to the belief that FCs give women 'choice' and 'control. ${ }^{15}$ These studies, albeit small and non-generalisable, suggest a need for further investment in supporting providers to counsel and offer women the FC.

In this nationally representative study of physicians and nurses, we examined FC counselling and provision practices in South Africa and Zimbabwe. The two countries have different histories of FC introduction that could impact provision at the health service level. Zimbabwe was one of the first countries to introduce FCs in 1997 through the public sector and innovative social marketing campaigns. Scale-up of male condoms and FCs in recent years has been based on a national comprehensive behaviour change strategy to reduce sexual transmission of HIV, and FCs are now offered in all public sector facilities. ${ }^{16}{ }^{17} \mathrm{FC}$ distribution in the public sector in Zimbabwe increased from about 400000 in 2005 to more than 2000000 in 2008 and social marketing sales have risen from about 900000 in 2005 to more than 3000000 in 2008. ${ }^{16}$ South Africa introduced the FC shortly after Zimbabwe in 1998 primarily through public sector family planning clinics and communitybased programmes. ${ }^{18}$ FC distribution in South Africa is among the highest in the world (4.3 million FCs distributed in public sector in 2008) ${ }^{19}$ however, FCs are not yet available in all public sector facilities in South Africa and proportional to population size (the population of South Africa is approximately four times that of 
Zimbabwe), Zimbabwe has higher distribution rates. Given these distribution efforts to increase stocking and availability in both countries, we still lack national estimates of how many providers are able to offer FCs to patients.

We investigated counselling and provision practices among a nationally representative sample of providers to gauge the prevention services offered to a range of patients in varied clinical settings. We assessed whether providers view FCs as more appropriate for certain types of patients, and how their FC counselling practices varied compared to those for male condoms. The results have the potential to inform efforts to prepare providers to expand access to this female-initiated prevention method for their patients.

\section{METHODS}

This study is part of a mixed-methods research project in Southern Africa investigating providers' pregnancy and STI/HIV prevention practices. We completed national probability surveys of physicians and nurses in South Africa and Zimbabwe in 2009. Participants answered a series of questions on female and male condoms counselling and provision practices, as well as demographic and professional practice characteristics and patient population. The surveys were preceded by 60 in-depth interviews of providers serving female patients at risk of HIV, which revealed their views of FC use within their patient populations.

We used a multistage, facility-based approach to generate a national probability survey sample of providers. We randomly selected districts (with probability proportional to size, based on estimated numbers of physicians and nurses), then facilities that provided family planning or HIV/STI services within those districts (stratified by type-hospital or clinic-and probability proportional to size), and recruited all providers from those facilities who provided family planning or HIV/STI services. The sample consists of public facilities in South Africa and Zimbabwe. Some non-governmental organisations are included in Zimbabwe as they deliver primary care, and specifically family planning, to low-income populations. The final sample included 1019 providers representing 116 facilities (or $89 \%$ of the total 130 selected facilities) from South Africa and 953 providers representing 130 facilities from Zimbabwe (94\% of the total 138 facilities selected). The methodology has been described in detail elsewhere. ${ }^{20}$

Data were collected via self-administered questionnaires distributed in-person in Zimbabwe and telephoneadministered questionnaires in South Africa (costs of in-person visits were prohibitive owing to the large country size). Approvals were granted as required in each country, at the national, provincial, district and facility levels. In South Africa, provincial approval was granted, as well as district-level approval where required by the facility. In Zimbabwe, approval was granted at the national level, and either the provincial or district level, as needed. The study was approved by the University of KwaZulu-Natal Biomedical Research Ethics Administration, the Medical Research Council of Zimbabwe, the Western Institutional Review Board and the University of California, San Francisco Committee on Human Research.

Providers were asked whether they currently provide the FC and the male condom, and whether they would like to receive more training (yes/no). Providers were also asked about the frequency of female (and male) condom counselling, on a four-point Likert scale (never, sometimes, usually or always), with the following types of female patients: women in general, female teenagers, HIV-positive women, married women, unmarried women and women using hormonal contraception. They were asked whether they believe FCs are appropriate contraceptives for women at risk of HIV infection (yes/no) and HIV-positive women (yes/no), whether they routinely talk to female patients about pregnancy and HIV/STI prevention during the same visit (yes/no), and how much of a need there is for more female barrier methods for HIV/STI prevention (on a scale of 1-10).

We assessed clinician practices by country for different types of female patients in these high HIV prevalence settings, using $\chi^{2}$-statistics for categorical variables and t tests for continuous variables. We analysed condom counselling practices with multivariable logistic regression to assess FC counselling by provider and practice-related characteristics. We also analysed male condom counselling practices for comparison using the same set of predictors. The two outcome variables were routine (usually/always) counselling on FCs and routine counselling on male condoms. We adjusted analyses for the facility-based sampling scheme to account for clustering at the facility level. We used Stata V.11.0 (College Station, Texas, USA) for analyses. Significance was defined as $\mathrm{p}<0.05$. We conducted thematic analysis of qualitative data to investigate openended provider responses about their counselling and provision practices.

\section{RESULTS}

A total of 614 providers from South Africa and 830 providers from Zimbabwe completed the survey $(\mathrm{N}=1444)$ with an overall response rate of $73.2 \%$. In South Africa, the response rate did not differ between hospitals (61\%) and clinics $(60 \%)$, though nurses were more likely to respond than physicians (66\% vs 39\%). In Zimbabwe, providers in hospitals were more likely to respond than in clinics (92\% vs $81 \%$ ), and physicians were more likely to respond than nurses $(100 \%$ vs $87 \%)$. The most common reason for not responding was busy clinic load or that the staff were not at the clinic. The majority surveyed in both countries were nurses $(91 \%$; table 1$) .{ }^{17}$ Ninety-six per cent of the nurses were female, and overall $86 \%$ of participants were female. Most reported prior training in HIV prevention $(80 \%)$ and family planning $(63 \%)$. Participants were split between hospital 


\begin{tabular}{|c|c|c|c|}
\hline & $\begin{array}{l}\text { Zimbabwe } \\
(n=830)\end{array}$ & $\begin{array}{l}\text { South Africa } \\
(n=614)\end{array}$ & $\begin{array}{l}\text { Total } \\
(\mathrm{N}=1444)\end{array}$ \\
\hline \multicolumn{4}{|l|}{ Gender, n (\%) } \\
\hline Female & $674(82)$ & $547(90)$ & $1221(86)$ \\
\hline Male & $145(18)$ & $62(10)$ & 207 (15) \\
\hline \multicolumn{4}{|l|}{ Provider type, n(\%) } \\
\hline Nurse & $792(95)$ & $528(86)$ & $1320(91)$ \\
\hline Physician & $38(5)$ & $86(14)$ & $124(9)$ \\
\hline Age, median years (range) & $39(20-74)$ & $43(23-69)$ & $41(20-74)$ \\
\hline \multicolumn{4}{|l|}{ Previous training, $\mathrm{n}(\%)$} \\
\hline HIV prevention & $629(77)$ & $510(84)$ & $1139(80)$ \\
\hline Family planning & $503(61)$ & $399(66)$ & $902(63)$ \\
\hline \multicolumn{4}{|l|}{ Type of facility, n (\%) } \\
\hline Hospital & $484(59)$ & $309(50)$ & $793(55)$ \\
\hline Clinic & $342(41)$ & $305(50)$ & $647(45)$ \\
\hline \multicolumn{4}{|l|}{ Location, n (\%) } \\
\hline Urban & $375(45)$ & $315(51)$ & $690(48)$ \\
\hline Rural & $451(55)$ & $299(49)$ & $750(52)$ \\
\hline \multicolumn{4}{|c|}{ Proportion of patients at risk for HIV, n (\%) } \\
\hline None/some & $175(22)$ & $46(8)$ & $221(16)$ \\
\hline Half & $112(14)$ & $92(15)$ & $204(14)$ \\
\hline Most/all & $524(65)$ & $470(77)$ & $994(70)$ \\
\hline
\end{tabular}

(55\%) and clinic (45\%) settings, and urban (48\%) and rural $(52 \%)$ areas. Virtually all providers served adult women of reproductive age $(99.7 \%)$, female teens $(98 \%)$ and the majority also saw male patients (86\%). The majority $(70 \%)$ reported that most or all of their patients are at risk for HIV.

Almost all (99\%) providers reported currently offering male condoms to patients (table 2). A large majority in both countries $(88 \%)$ reported offering FCs, with a lower proportion in South Africa $(80 \%)$ than Zimbabwe (94\%; $\mathrm{p} \leq 0.001)$. While most physicians offer FCs $(72 \%)$, a significantly higher proportion of nurses do $(89 \%$; $\mathrm{p} \leq 0.001)$. Availability is an important factor in being able to offer a method, and $27 \%$ of providers reported they would offer FCs if more easily available. Among the small proportion currently not offering FCs $(13 \% \mathrm{n}=169), 68 \%$ in South Africa reported they would if it were more easily available and $54 \%$ in Zimbabwe. More providers in South Africa (28\%) than Zimbabwe (14\%) reported that they would like training on FCs $(\mathrm{p} \leq 0.001)$.

Seventy-one per cent reported routinely counselling (usually or always) women on FCs; more providers reported FC counselling for HIV-positive $(82 \%)$ and unmarried women $(74 \%)$, and fewer reported counselling for married women (66\%), women using hormonal contraception $(65 \%)$, and female adolescents (55\%). Most of these differences in counselling by patient type were owing to large variations in Zimbabwe where counselling for HIV-positive women was 93\%, but for adolescents was $50 \%$ (table 2). In South Africa, there was a lower level of routine counselling in general $(62 \%)$, with little difference among the patient types, ranging from $67 \%$ of HIV-positive women to $62 \%$ of adolescents.
However, 90\% of providers in South Africa reported routine male condom counselling with female patients compared with $80 \%$ in Zimbabwe. Similar withincountry counselling patterns held true for male condoms, with $94 \%$ routinely counselling female adolescents in South Africa compared to 56\% in Zimbabwe.

Support for the FC as a contraceptive method for HIV-positive women or women at risk of HIV infection was high overall; in Zimbabwe there was near universal support for women at risk of HIV infection $(98 \%$ vs $84 \%$ in South Africa; $\mathrm{p} \leq 0.001)$ or HIV-positive women $(97 \%$ and $87 \%$, respectively; $\mathrm{p} \leq 0.001$; table 2 ). The large majority $(89 \%)$ reported routinely talking to female patients about pregnancy and HIV/STI prevention in the same visit. About two-thirds of providers (68\%) believed there is a very high ( 9 or 10 on a scale of $1-10$ ) need for more female barrier methods for HIV/STI prevention.

In multivariable logistic regression, several provider characteristics were found to be significantly associated with routine condom counselling (table 3). Providers in South Africa were significantly less likely to counsel female patients on the $\mathrm{FC}(\mathrm{OR}=0.48 ; \mathrm{p} \leq 0.001)$, and more likely to counsel on the male condom $(\mathrm{OR}=2.4$; $\mathrm{p} \leq 0.001)$. Provider age was positively associated with FC counselling $(\mathrm{OR}=1.02 ; \mathrm{p} \leq 0.001)$, and nurses were significantly more likely than physicians to counsel patients on both FCs $(\mathrm{OR}=5.4 ; \mathrm{p} \leq 0.001)$ and male condoms $(\mathrm{OR}=2.6 ; \mathrm{p} \leq 0.001)$. HIV prevention training and family planning training were not associated with FC counselling. HIV prevention training was associated with male condom counselling in bivariate models, but in the multivariable models including a variable for proportion of 
Table 2 Condom counselling and provision practices and female condom beliefs

\begin{tabular}{|c|c|c|c|}
\hline & $\begin{array}{l}\text { Zimbabwe } \\
(\mathrm{n}=830)\end{array}$ & $\begin{array}{l}\text { South Africa } \\
(\mathrm{n}=614)\end{array}$ & $\begin{array}{l}\text { Total } \\
(\mathrm{N}=1444)\end{array}$ \\
\hline \multicolumn{4}{|l|}{ Currently offers condoms, $\mathrm{n}(\%)$} \\
\hline Female condoms ${ }^{\star * *}$ & $756(94)$ & $483(80)$ & $1239(88)$ \\
\hline Male condoms & $796(99)$ & $599(99)$ & $1395(99)$ \\
\hline Would offer female condoms if more easily available, $\mathrm{n}(\%)$ & $230(31)$ & $129(22)$ & $359(27)$ \\
\hline \multicolumn{4}{|c|}{ Among providers offering female condoms, counsels routinely with..., $n(\%)(\mathrm{N}=1226)$} \\
\hline Women in general ${ }^{\star \star \star}$ & $602(80)$ & $329(69)$ & $931(76)$ \\
\hline Female teenagers ${ }^{\star \star *}$ & $377(50)$ & $328(69)$ & $705(58)$ \\
\hline HIV-positive women*** & $711(95)$ & $352(74)$ & $1063(87)$ \\
\hline Married women ${ }^{\star * *}$ & $544(72)$ & $319(67)$ & $863(70)$ \\
\hline Unmarried women $* * *$ & $622(83)$ & $342(72)$ & $964(79)$ \\
\hline Women using hormonal contraception & $500(67)$ & $336(71)$ & $836(68)$ \\
\hline \multicolumn{4}{|l|}{ Among all providers, counsels routinely on female condoms with..., $\mathrm{n}(\%)$} \\
\hline Women in general ${ }^{* * *}$ & $635(78)$ & $370(62)$ & $1005(71)$ \\
\hline Female teenagers ${ }^{* * *}$ & $403(50)$ & $372(62)$ & $775(55)$ \\
\hline HIV-positive women*** & $761(93)$ & $400(67)$ & $1161(82)$ \\
\hline Married women ${ }^{\star * \star}$ & $573(70)$ & $358(60)$ & $931(66)$ \\
\hline Unmarried women $* * *$ & $658(81)$ & $385(64)$ & $1043(74)$ \\
\hline Women using hormonal contraception & $529(65)$ & $380(64)$ & $909(65)$ \\
\hline \multicolumn{4}{|c|}{ Among all providers, counsels routinely on male condoms with..., $n(\%)$} \\
\hline Women in general ${ }^{\star \star *}$ & $652(80)$ & $542(90)$ & $1194(84)$ \\
\hline Female teenagers ${ }^{\star \star *}$ & $448(56)$ & $565(94)$ & $1013(72)$ \\
\hline HIV-positive women & $786(97)$ & $578(96)$ & $1364(96)$ \\
\hline Married women ${ }^{\star * *}$ & $610(75)$ & $514(85)$ & $1124(79)$ \\
\hline Unmarried women ${ }^{\star \star *}$ & $683(85)$ & $554(92)$ & $1237(88)$ \\
\hline Women using hormonal contraception ${ }^{\star \star \star}$ & $537(66)$ & $535(90)$ & $1072(76)$ \\
\hline $\begin{array}{l}\text { Believes female condoms appropriate contraception for women at risk } \\
\text { of HIV infection, } n(\%)^{\star \star *}\end{array}$ & $800(98)$ & $503(84)$ & $1303(92)$ \\
\hline $\begin{array}{l}\text { Believes female condoms appropriate contraception for HIV-positive } \\
\text { women, } \mathrm{n}(\%)^{\star \star \star}\end{array}$ & $794(97)$ & $519(87)$ & $1313(93)$ \\
\hline $\begin{array}{l}\text { Routinely talks to female patients about pregnancy and HIV/STI } \\
\text { prevention in same visit, } \mathrm{n}(\%)\end{array}$ & $718(88)$ & $536(90)$ & $1254(89)$ \\
\hline \multicolumn{4}{|c|}{ Believes there is a need for more female barrier methods for HIV/STI prevention, scale $1-10, n(\%)$} \\
\hline High $(9-10)$ & $537(67)$ & $412(70)$ & $949(68)$ \\
\hline Medium-high (7-8) & $140(17)$ & $102(17)$ & $242(17)$ \\
\hline Medium (5-6) & $72(9)$ & $45(8)$ & $117(8)$ \\
\hline Medium-low (3-4) & $23(3)$ & $7(1)$ & $30(2)$ \\
\hline Low (1-2) & $35(4)$ & $23(4)$ & $58(4)$ \\
\hline \multicolumn{4}{|l|}{ Would like training on condoms, $n(\%)$} \\
\hline Female condoms ${ }^{\star \star \star}$ & $112(14)$ & $165(28)$ & $277(20)$ \\
\hline Male condoms ${ }^{\star * *}$ & $56(7)$ & $109(18)$ & $165(12)$ \\
\hline
\end{tabular}

patients at risk of HIV (most/all), HIV training was no longer significant, although high proportion of patients at risk of $\mathrm{HIV}$ was $(\mathrm{OR}=1.6 ; \mathrm{p} \leq 0.001)$. Condom counselling did not vary by urban versus rural clinical setting or in clinics or hospitals.

The in-depth interviews gave some insight into the reasons that some providers might include the FC in counselling, while others might not, and what they think the best approach is to encourage use. Many providers mentioned logistical factors in the interviews that would restrict access to the method. Providers noted that FCs are more expensive than male condoms and are not always supplied to clinics, especially in South Africa, where availability was frequently mentioned as a problem. Several considered physical features as method limitations, including discomfort and being highly visible.

Alternatively, many providers noted that some men who will not use a male condom will agree to an FC, since the women puts it on. Providers noted that the FC could help empower women since they could ensure it was used, although they also mentioned that trust issues related to marriage and condom use arise with the FC and male condom. Many providers thought that husbands might be more willing to try FCs if they came with their wives to the clinic and were shown by the provider how to use it. As a Zimbabwe physician said: “...the method is a bit awkward. It's quite difficult to use, so it really remains for us to encourage the partner to 


\begin{tabular}{|c|c|c|}
\hline Routine condom counselling (usually/always) & Female condoms OR (95\% Cl) & Male condoms OR $(95 \% \mathrm{CI})$ \\
\hline \multicolumn{3}{|l|}{ Country } \\
\hline Zimbabwe (reference) & - & - \\
\hline South Africa & $0.48^{* * *}(0.35$ to 0.68$)$ & $2.39^{\star \star *}(1.57$ to 3.65$)$ \\
\hline Age (years) & $1.02^{\star \star \star}(1.02$ to 1.05$)$ & 1.01 (1.00 to 1.03$)$ \\
\hline \multicolumn{3}{|l|}{ Provider type } \\
\hline Physician (reference) & - & - \\
\hline Nurse & $\overline{5.41^{\star \star \star}}(3.26$ to 8.98$)$ & $\overline{2.60^{\star \star}}(1.47$ to 4.58$)$ \\
\hline Trained in HIV prevention & $0.90(0.62$ to 1.05$)$ & $1.35(0.87$ to 2.08$)$ \\
\hline Trained in family planning & $0.98(0.71$ to 1.35$)$ & $1.02(0.70$ to 1.51$)$ \\
\hline \multicolumn{3}{|l|}{ Facility type } \\
\hline Hospital (reference) & - & - \\
\hline Clinic & $0.88(0.61$ to 1.25$)$ & $1.21(0.76$ to 1.94$)$ \\
\hline \multicolumn{3}{|l|}{ Location } \\
\hline Rural (reference) & - & - \\
\hline Urban & $0.85(0.61$ to 1.25$)$ & $1.42(0.93$ to 2.14$)$ \\
\hline Most/all patients at HIV risk & 1.21 (0.92 to 1.59$)$ & $1.58^{\star \star}(1.12$ to 2.22$)$ \\
\hline$\chi^{2}$ (8 degrees of freedom) & 96.08 & 70.24 \\
\hline $\mathrm{N}$ & 1324 & 1328 \\
\hline
\end{tabular}

accompany the lady to the surgery for consultation so that we can have some kind of counselling between myself and the couple." While counselling the couple was frequently brought up by providers, in one clinic the provider also mentioned clinic support groups with peer counselling to help women to initiate condom use. In the interviews most providers explained that in counselling adolescents, they discussed abstinence and saying no to sex before marriage, which may explain the finding in the survey data or lower counselling of adolescents on condom use in Zimbabwe. Some, however, also mentioned condoms, after abstinence, and in South Africa, most providers in the interviews reported they counselled adolescents on abstinence and condoms.

\section{DISCUSSION}

The FG was integrated into provider practices in Southern Africa, but to a lesser extent than the male condom. Providers in Zimbabwe reported counselling patients on FCs significantly more than providers in South Africa, which is likely attributable to the larger public sector FC programme in Zimbabwe, relative to population size. Providers across South Africa may have been less likely to have learnt about the FC owing to the geographic distance and smaller FC programme per population. In South Africa, the government has focused on reaching certain designated clinics with supplies and training so availability is not yet ubiquitous. In the South African qualitative data, many providers commented that availability in the clinic is still a problem, although the majority reported in the national survey that if FCs were more easily available, they would offer them. As in a previous study from Kenya, ${ }^{14}$ providers from both countries noted in interviews that the FC was not always available in clinics even though it was distributed in the public sector. FCs, a basic technology, had counselling patterns that were similar in rural and urban areas and clinics and hospitals, unlike for more sophisticated technologies which in general are more available to urban populations or in hospital settings.

Variations in counselling by patient type were wide in Zimbabwe, with high levels of counselling for HIV-positive women. In Zimbabwe, providers were much less likely to report female and male condoms counselling with adolescents than with women in general, suggesting the need for provider training emphasising the importance of education of adolescents on safe sex, perhaps even prior to sexual initiation; less than half of Zimbabwe adults in the 2010-2011 Demographic and Health Surveys (DHS), however, supported condom education for 12-year-olds to 14 -year-olds. ${ }^{7}$ Zimbabwe providers were also less likely to report condom counselling with women using hormonal contraception, signalling the need for emphasis on dual protection of STIs and pregnancy. In both countries, providers were less likely to counsel married women than unmarried women on FCs, although it is essential to give all women information in these high-prevalence settings as many married women are at risk of acquiring HIV from their marital partner. Condom use is less common among married women, although one study of a condom intervention (female and male) showed increased use among HIV-positive married women. ${ }^{21}$ There were some signs in the qualitative data that providers thought FCs might be more acceptable in marriage than male condoms in some cases where the woman would be willing to make the effort and ensure their use was consistent. However, 
providers noted trust issues may also arise with FCs. Another early study from the US identified similar training needs among providers who saw FCs as appropriate for only certain groups of women, such as HIV-positive women. ${ }^{13}$

A number of providers reported a desire for more FC training, signalling the need for continued investment in programmes and policies to support access to the FC in both countries. Previous research from South Africa has demonstrated the positive impact of training on provider attitudes. ${ }^{13}$ Our results showed that neither having previous HIV training nor serving a high proportion of at-risk patients significantly increased likelihood of provider counselling on FCs. Efforts should be made to ensure that HIV and family planning training in both countries include FCs, given the wider availability of supplies in recent years. The finding that nurses were significantly more likely than physicians to report counselling women on both male condoms and FCs reflects the prominent role that nurses play in prevention counselling; nurses therefore should be a priority for training as they deliver much of the primary care. However, physicians should also be prepared to counsel women and men about their options for dual protection against pregnancy and STIs.

Providers reported a strong need for new femaleinitiated barrier methods for prevention and, similar to prior research from the USA and South Africa, ${ }^{13}$ several providers demonstrated negative attitudes about the aesthetics and use of the FC during qualitative interviews. This finding suggests that current technologies may not meet all their patient needs or are not adequately well known or accessible, though it is important to note that this research was conducted just before the new FC2 was approved by the USFDA. The reported desire for training suggests that even as we work to develop new technologies, we must also invest in programmes and policies that ensure the potential for available existing technologies is achieved.

These findings must be considered in light of study limitations. We did not ask providers directly about stocking of FCs in their healthcare systems or whether they had prior training in FC counselling. Consequently, results do not shed light on how many providers in stocked clinics are providing patients with FC; rather, we only know how many providers overall, in both stocked and unstocked clinics, are offering the method. Provision in stocked clinics, especially with trained providers, is likely to be higher. Expense to the health system and availability at the clinic level (in addition to whether they have had prior training on FC provision) would influence their ability to provide them and thus the likelihood that they counsel patients. Since providers are reporting on their counselling practices, it is likely that social desirability bias influenced responses towards more comprehensive levels of prevention counselling; therefore, patients for whom we measured low levels of counselling are likely to be in even greater need of FC education. Our study also has important strengths. Our nationally representative surveys (with relatively high response rates) allow us to generalise about providers' counselling and provision practices in these two countries; this is the first research on FC counselling and provision in Southern Africa to include representative national samples of providers. Further, very few data existed previously on FC counselling and provision in sub-Saharan Africa overall and our study contributes significantly to the literature on this topic by providing information on current provider practices in two high HIV-prevalence countries.

As discussed by Mantell et $a l^{22}$ a number of previous studies have documented the role of providers as 'gatekeepers' to new products and the influence that provider acceptance of new prevention methods can have on their successful introduction and uptake. Thus provider practices and support are essential to the successful integration of the FC into HIV and family planning services, and ultimately to ensure women can protect themselves from both STI infection and unintended pregnancy. Our findings revealed provider support for the FC as a dual-protection method, and a significant need for further work promoting provider counselling in particular with adolescents, married women and women using hormonal contraception.

\section{Author affiliations}

${ }^{1}$ Department of Society, Human Development, and Health, Harvard School of Public Health, Boston, Massachusetts, USA

${ }^{2}$ Ibis Reproductive Health, Cambridge, Massachusetts, USA

${ }^{3}$ Ibis Reproductive Health, Johannesburg, South Africa

${ }^{4}$ Department of Obstetrics and Gynecology, Centers for Disease Control and Prevention, Harare, Zimbabwe

${ }^{5}$ Department of Obstetrics, Gynecology and Reproductive Sciences, Bixby Center for Global Reproductive Health, University of California, San Francisco, California, USA

${ }^{6}$ HIV Prevention Research Unit, South African Medical Research Council, Durban, South Africa

Acknowledgements We gratefully acknowledge the National Institute of Child Health and Human Development for support of this study, NIH/NICHD R01 HD046027. Its contents are solely the responsibility of the authors and do not necessarily represent the official views of the NIH. We are thankful to our field staff and the thoughtful contributions of our study participants. Data presented at the American Public Health Association annual meeting, Denver, 2010.

Contributors $\mathrm{CCH}, \mathrm{KB}, \mathrm{TC}, \mathrm{TN}, \mathrm{GR}$ and M B contributed to the conception and design and all authors, including NM, contributed to the interpretation of data. LS and CCH conducted the analysis. Kelsey Holt wrote the article. All authors revised the article critically for important intellectual content and gave the final approval of the version to be published. $\mathrm{CCH}$ was responsible for planning, conduct, reporting and overall content of the study.

Funding NIH funded the study, but had no role in data collection, analysis or interpretation.

\section{Competing interests None.}

Ethics approval The study was approved by the University of KwaZulu-Natal Biomedical Research Ethics Administration, the Medical Research Council of Zimbabwe, the Western Institutional Review Board and the University of California, San Francisco Committee on Human Research.

Provenance and peer review Not commissioned; externally peer reviewed. 
Data sharing statement Extra data can be accessed via the Dryad data repository at http://datadryad.org/ with the doi:10.7272/Q6BG2KWF.

\section{REFERENCES}

1. Kurth AE, Celum C, Baeten JM, et al. Combination HIV prevention: significance, challenges, and opportunities. Curr HIV/AIDS Rep 2011;8:62-72.

2. Vijayakumar G, Mabude Z, Smit J, et al. A review of female-condom effectiveness: patterns of use and impact on protected sex acts and STI incidence. Int J STD AIDS 2006;17:652-9.

3. Abdool Karim Q, Abdool Karim S, Frohlich J, et al. Effectiveness and safety of tenofovir gel, an antiretroviral microbicide, for the prevention of HIV infection in women. Science 2010;329:1168.

4. CDC. CDC issues interim guidance on use of medication to prevent HIV infection among heterosexually active adults. 2012 [cited 05 Dec 2012]. http://www.cdc.gov/nchhstp/newsroom/2012/PrEPHeterosexualGuidance-PressRelease.html (accessed 5 Dec 2012).

5. UNAIDS. UNAIDS outlook 2010. Switzerland: Joint United Nations Programme on HIV/AIDS, 2010.

6. Shisana O, Rehle T, Simbayi LC, et al. South African national HIV prevalence, incidence, behaviour and communication survey, 2008: a turning tide among teenagers? Cape Town: HSRC Press, 2009.

7. Zimbabwe National Statistics Agency, International ICF. Zimbabwe Demographic and Health Survey 2010-11. Calverton, MD: ZIMSTAT and ICF International Inc, 2012.

8. Sedgh G, Hussain R, Bankole A, et al. Women with an unmet need for contraception in developing countries and their reasons for not using a method. Occas Rep 2007;37:5-40.

9. Department of Health, Medical Research Council, OrcMacro. South African Demographic and Health Survey 2003. Praetoria: Department of Health, 2007.

10. Peters A, Jansen W, Van Driel F. The female condom: the international denial of a strong potential. Reprod Health Matters 2010;18:119-28.
11. CHANGE. Female condoms and U.S. foreign assistance: an unfinished imperative for women's health. Washington, DC: Center for Health and Gender Equity, 2011.

12. Reproductive Health Supplies Coalition. Female Condom Product Brief. Caucus on New and Underused Reproductive Health Technologies. Brussels, Belgium: Reproductive Health Supplies Coalition, 2012

13. Mantell JE, Hoffman S, Weiss E, et al. The acceptability of the female condom: perspectives of family planning providers in New York City, South Africa, and Nigeria. J Urban Health 2001;78:658-68.

14. Mung'ala L, Kilonzo N, Angala $P$, et al. Promoting female condoms in HIV voluntary counselling and testing centres in Kenya. Reprod Health Matters 2006;14:99-103.

15. Kaler A. "It's some kind of women's empowerment": the ambiguity of the female condom as a marker of female empowerment. Soc Sci Med 2001;52:783-96.

16. UNFPA. HIV prevention gains momentum: success in female condom programming. New York: UNFPA, 2011.

17. CHANGE. Female condoms: lessons from Zimbabwe. Washington, DC: Center for Health and Gender Equity, 2010.

18. FHI. Female condom introduction in South Africa. Durham: Family Health International, 2007.

19. Republic of South Africa. Country progress report on the declaration of commitment on HIVIAIDS. Republic of South Africa: Department of Health, 2010.

20. Harper C, Holt K, Nhemachena T, et al. Willingness of clinicians to integrate microbicides into HIV prevention practices in Southern Africa. AIDS Behav 2012;16:1821-9. Published Online First: 1 January 2012. doi:10.1007/s10461-011-0109-6

21. Callegari L, Harper CC, Van der Straten A, et al. Consistent condom use in married Zimbabwean women after a condom intervention. Sex Transm Dis 2008;35:624-30.

22. Mantell JE, Scheepers E, Abdool Karim Q. Introducing the female condom through the public health sector: experiences from South Africa. AIDS Care 2000;12:589-601. 